\title{
Validation of ECG-derived heart rate recordings in Atlantic cod (Gadus morhua L.) with an implantable data logging system
}

Ásgeir Bjarnason 1* ${ }^{*}$, Andrés Gunnarsson?', Tómas Árnason², Matthías Oddgeirsson², Anton Björn Sigmarsson and Ásgeir Gunnarsson ${ }^{3}$

\begin{abstract}
Background: Archival tags have been used on fish for a number of years to measure temperature, pressure and salinity, among other parameters. Measurements of heart rate in fish can be used in a wide variety of biological and ecological studies, e.g., for evaluating short- and long-term effects of stressful conditions involved with fishing and farming practices, or events that are non-related to human activity, such as predator-prey interactions. Furthermore, if a relationship between temperature, heart rate and metabolic rate has been established there are potentials to establish long-term bioenergy models that include seasonal effects on feeding, locomotion, spawning and migration. However, heart-rate measurements in fish have been difficult to conduct in the wild due to lack of commercial availability, large size of the recording systems, difficulties with proper placement of external electrodes and restriction in setup with external systems. This work presents a validation of a commercial ECG (Electrocardiogram)-derived heart rate data logger on farmed Atlantic cod. This validation focuses on assessing the logger's signal processing algorithm and recording quality.

Results: The eight fish studied showed both individual periodical variation, as well as individual baseline variation of the heart rate during the experimental period. Mean heart rate ranged from $29.9 \pm 6.3$ to $48.3 \pm 4.9 \mathrm{bpm}$, at $10.2 \pm 0.1^{\circ} \mathrm{C}$. This is comparable with previous research on Atlantic cod. The loggers were set up to record heart rate and temperature every $5 \mathrm{~min}$ and to store the ECG records used to calculate the heart rate every $30 \mathrm{~min}$. The quality index (QI), which is an algorithmic assigned value of the quality of the ECG, was used to filter the data set eliminating a total of 21,643 measurements (19\% of the recorded heart rate data). It was possible to manually calculate 18,490 out of 19,042 ECG records (97\%).
\end{abstract}

Conclusions: This study presented a validation of using a commercial implantable data logging device in Atlantic cod that records ECG, and can calculate both heart rate, and a novel quality index for the ECG record with an onboard algorithm.

Keywords: Cardiac, Heart rate, Atlantic cod, ECG, Implant, Data storage tag

\footnotetext{
*Correspondence: asgeir@star-oddi.com

${ }^{1}$ Star-Oddi Ltd., Garðabær, Iceland

Full list of author information is available at the end of the article
} 


\section{Background}

For fish, temperature is the main abiotic factor that determines the metabolic rate $[1,2]$, while heart rate is the key element in the temperature-dependent regulation of blood flow [3, 4]. In experimental situations, studies have shown a relationship between temperature, heart rate and oxygen consumption that has been used to estimate metabolic rate for several fish species [5-7]. However, the ability of many fish species to increase the cardiac output via stroke volume without an increase in heart rate has made it difficult to formulate a unifying hypothesis about how the temperature-dependent changes in heart rate affect the calibrated metabolic rate $[8,9]$. Besides temperature and physiological variables such as blood pressure and oxygen uptake, calibrated metabolic rate in fish is also affected by individual differences, feeding, and stress $[10,11]$. These variables influence the heart rate and question the estimate of calibrated metabolic rate in long-term studies [12-14]. Therefore, further experimental research is required to examine the relationship between heart rate and metabolic rate where different variables are included with temperature.

In ecological studies of fish, calculations of metabolic rates can be used to create bioenergy models [15] that can be connected to seasonal feeding, spawning, locomotion or migration, as well as the influence of stressors such as predators or human-induced stressors such as recreational or commercial fishing.

Where the before-mentioned relationship between temperature, heart rate and calibrated metabolic rate exist, the ability to telemeter or record heart rate information from fish in their natural habitat through archival tags or other means such as acoustic transmission or satellite transmission promises to open many new areas of research on fish energetics. Extensive data from temperature and depth loggers exist for wild Atlantic cod in the North Atlantic Ocean [16-18], but for wild Atlantic cod only a single short-term field experiment has been published on heart rate data using a combination of the devices described in this paper and acoustic transmitting tags to measure the effect of sound exposure from a seismic airgun on heart rate, acceleration and depth in freeswimming Atlantic cod [19].

Heart rate recording in fishes has been difficult to conduct in the wild due to a number of reasons such as large size of the recording systems, restrictions due to setup with an external system, proper placement of external electrodes, and the lack of commercial availability [15, 20-23]. External ECG electrodes have been used successfully with heart rate loggers for up to 32 days on a single largemouth bass [24]; however, the authors noted that 32 days is approaching the limit for deployment with external device due to issues with fouling by aquatic vegetation and other debris. They also note that the silk sutures used to immobilize the external electrode wires would eventually be rejected as part of the active healing process of the fish. Campbell et al. [25] made a 21-day comparison study between internal and external electrode placement using a custom-made ECG-based data logger on Black cod (Paranothenia angustata). They concluded that the external attachment had less effect on the swimming activity and physiological stress then the internally implanted device. However, it was deemed probable that bottom-dwelling lifestyle of the black cod increased the chances of infection in the ventral incision as wound was in contact with the seabed which allowed entry of foreign bodies.

Cooke et al. [15] made an overview of heart rate sensors that have been used in fish over the last 5 decades. Although limited technical information is available on commercial devices, published data do exist on the five following devices:

1. Vemco heart-rate transmitters used on Atlantic cod in $[6,24]$ and further described in [26] which uses an analog peak detector to calculate heart rate recorded from two silver-tipped or stainless-steel electrodes surgically placed externally $0.5-1.0 \mathrm{~cm}$ apart in the pericardial cavity.

2. Lotek heart-rate transmitters were used on Atlantic Salmon in [27] where the transmitter was placed in the abdominal cavity with a trailing antenna brought out through the fish. Electrodes were gold-plated and were inserted within the pericardial cavity through small holes in the lepidotrichs bone of the pectoral girdle. It is not mentioned how heart rate is calculated.

3. HRTDL used to measure heart rate in Murray cod [28]. A detailed description of the device exists [29] which uses an analog peak detector to calculate heart rate recorded from two electrodes placed approximately $40 \mathrm{~mm}$ apart. One electrode is placed closed to the heart and the other in the abdominal cavity with the device.

4. Thelma Biotel heart rate transmitter has no published results available, but the tag is pictured in [30] and has two wired electrodes presumably placed near or in the pericardium.

5. iLogR used by Clark et al. [23] in sockeye salmon that records 10.14 s traces of ECG at $200 \mathrm{~Hz}$ sampling frequency using two ECG electrodes placed ventral to the liver and as close as possible to the pericardial cavity.

None of the listed devices are presented currently on the manufacturer's homepage and no information 
is available on hardware parameters such as frequency response of the devices or amplification during the time of the study. For device number 3, Woakes et al. [29] describe three possible filter modes: $10-43 \mathrm{~Hz}$ for fur seal, $25-120 \mathrm{~Hz}$ for albatross and $20-80 \mathrm{~Hz}$ for gentoo penguin but it is unclear if another mode was used in [28]. Devices number 1-4 all seem to use a similar approach to calculate heart rate which is an analog or digital method with no possibility to view the ECG traces of the data. Device number 5 has the greatest resemblance to the milli-HRT presented in this study as it records full ECG records and relies on post processing of the ECG data to derive heart rate.

The aim of this study was to present a validation of the signal processing algorithm as well as the recording quality of a commercial ECG-derived heart rate data logging system on farmed Atlantic cod. Although the logging system is being tested on farmed cod for 8 weeks, this system is leadless and designed to function on wild free-swimming individuals for over a year. The system can grade the heart rate calculations based on a novel quality index (QI) grading scheme which is validated through ECG recordings which are stored in the memory of the logger.

\section{Methods}

\section{Heart rate loggers and data collection}

The data loggers used in the study were DST milliHRT V7 ( $W=11.8 \mathrm{~g}, L=39.5 \mathrm{~mm}, W=13 \mathrm{~mm}, 11.8 \mathrm{~g}$, Star-Oddi, Iceland) heart rate and temperature loggers. Signal acquisition is through a single-channel ECG amplifier circuit with a bandpass filter of $(-3 \mathrm{~dB})$ at 0.5-140 Hz. Recording electrodes are platinum-based and spaced $15 \mathrm{~mm}$ apart. The data logger has a PanTompkins [31]-based on-board algorithm that does real-time QRS detection from the ECG signal that is recorded in small bursts which depend upon the sampling frequency of the ECG. In this study the sampling frequency of the ECG signal was $100 \mathrm{~Hz}$ which correlates to a $6 \mathrm{~s}$ recording. The sampling interval was set to record heart rate and temperature every $5 \mathrm{~min}$ and to store the raw ECG recordings every 30 min for 8 weeks. The memory of the data logger can store up to 2787 ECG data records but has the memory capacity to store 699,051 temperature and heart rate recordings, the battery size being the limiting factor. The milli-HRT is limited to about 21,000 heart rate and temperature records sampling at $100 \mathrm{~Hz}$. The temperature sensor has a resolution of $0.032{ }^{\circ} \mathrm{C}$ and an accuracy of $\pm 0.2{ }^{\circ} \mathrm{C}$. The data logger is set up and downloaded using inductive radio frequency communication box with a download speed of 600 bytes/s.

\section{Fish holding and experimental procedures}

On April 18th, 2016 eight farmed Atlantic cod $(1787 \mathrm{~g} \pm 381 \mathrm{~g}, 50.8 \mathrm{~cm} \pm 5 \mathrm{~cm}$ ) were implanted with loggers and reared in captivity with other conspecifics for 52 days, in one gray circular tank $(2.9 \mathrm{~m}$ diameter $\times 0.9 \mathrm{~m})$. The fish were reared under continuous light (LD 24:0) with a light intensity of $80 \mathrm{~lx}$ at the surface. Aerated seawater (32 ppt) was provided in a flowthrough system and adjusted so that oxygen saturation was always close to $100 \%$. Commercial dry feed (Laxá Ltd), containing $53 \%$ crude protein and $15 \%$ crude fat was provided continuously over $20 \mathrm{~h}$ in moderate excess by automatic feeders.

After the initial measurements and tagging the fish were given 1 week to recover from the implantation at $9{ }^{\circ} \mathrm{C}$. Then the temperature was increased to $10.2^{\circ} \mathrm{C} \pm 0.1{ }^{\circ} \mathrm{C}$ and baseline measurements of heart rate recorded over 5 weeks.

After 5 weeks at $10.2{ }^{\circ} \mathrm{C}$ a stress test was initiated with 3 min of chasing the fish. Each fish was then netted and exposed to air for $1 \mathrm{~min}$ before being returned to the tank; an attempt to generate maximum heart rate response. All fish were stressed at approximately the same time, in the morning starting at 10:00. A similar method has previously been described in [32, 33]. Fish were allowed a $24 \mathrm{~h}$ recovery period after the stressors test after which the temperature was lowered to $7.1{ }^{\circ} \mathrm{C} \pm 0.1{ }^{\circ} \mathrm{C}$. After lowering the temperature, heart rates were monitored for five more days, or until the termination of the experiment on June 8th, 2016.

\section{Surgical procedure}

Prior to surgery the logger was sterilized in a Virkon ${ }^{\mathrm{TM}}$ solution, the logger was then rinsed thoroughly in deionized water and stored in a 70\% ethanol solution. Kruuse PGA EP 3.5 absorbable surgical suture was threaded through a hole at the front of the logger, used to anchor it in place which helps reduce noise generated by internal movement of the logger (Fig. 1a) and to keep it sufficiently close to the heart. Prior to surgery the fish were anaesthetized using MS-222 (0.1 g/l, Pharmaq Ltd). Once the fish lost equilibrium, the fish were weighed, measured and placed on a surgical bench. A $2-3 \mathrm{~cm}$ ventral incision was made between the pelvic fins and the logger was inserted into the visceral cavity. Within the visceral cavity the data logger was situated so that the parallel electrodes faced the outer wall and the wound was closed with one or two stitches (Fig. 1b). Antibiotic $(0.1 \mathrm{ml} / \mathrm{kg}$ tetracycline) and $1 \mathrm{ml}$ of vitamin B (Biocomplex ${ }^{\circledR}$ vet.) was injected into the visceral cavity through the wound. Finally, each fish was tagged with T-bar anchor tags with a $30 \mathrm{~mm}$ monofilament attachment and a $50 \mathrm{~mm}$ orange 

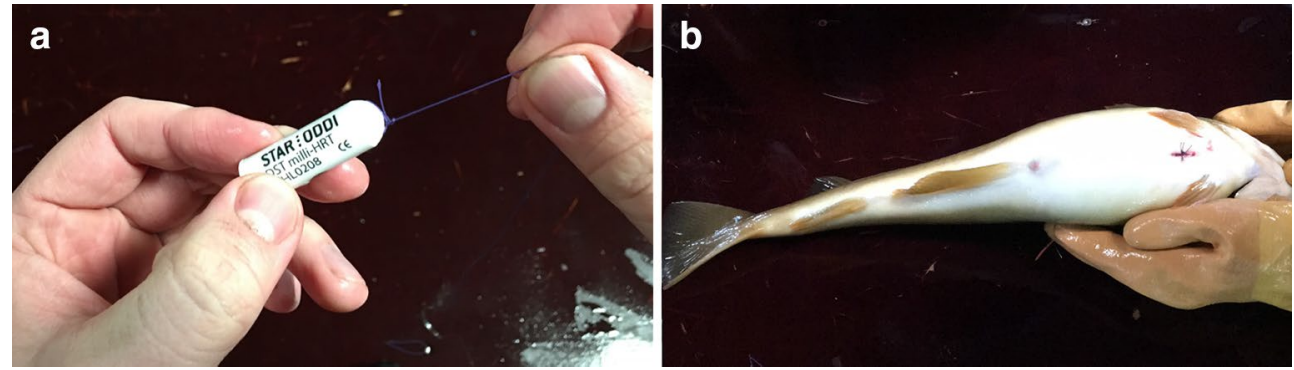

Fig. 1 a Suture is attached to the data logger which is then anchored to the body of the fish or the enclosure of the wound. b Atlantic cod fish implanted with milli-HRT between the pelvic fins

plastic tube with coding numbers (Hallprint Pty Ltd., Hindmarsh Valley, Australia) that was inserted into the dorsal musculature, before being returned to the holding tank. During the approximately 5 -min procedure, seawater with about $300 \%$ oxygen saturation was regularly poured over the gills to prevent suffocation.

\section{Data processing and validation}

The application software used to program the loggers and download the data from the loggers was Mercury V4.23 (Star-Oddi, Iceland). Heart-rate calculations were first validated by feeding frequencies from 0.5 to $5 \mathrm{~Hz}$ from a built-in cardiac signal generated with an Agilent 33500B signal generator to the electrodes of the tag. Then the $\mathrm{R}-\mathrm{R}$ interval of the QRS pulses was manually calculated and compared to the values calculated by the algorithm of the DST milli-HRT.

Heart-rate calculations from the study were manually validated for each fish, generating a total of 19,042 ECG data traces for the 8 fish. The software Pattern Finder (v. 1.11.0, Star-Oddi, Iceland) was used to manually calculate the interval between the QRS waveform, using a double cursor that outputs the interval in beats per minute. The heart-rate distribution of the manually calculated values was compared to all recorded values, a total of 114,357 recordings. Apart from the heart rate and temperature value, the logger also generates a quality index (QI) value with each heart rate calculation that is graded from 0 (best) to 3 (worst) using a set of simple rules such as: if there are at least two QRS peaks and variation between them is less than $20 \%$ the recording gets $\mathrm{QI}=0$, if there is only a single QRS peak detected or heart rate is calculated above a certain maximum or minimum value it gets the grade $\mathrm{QI}=3$. In other cases, a template-matching algorithm calculates the grade based on previous recordings which can output $\mathrm{QI}=0,1,2$ or 3 . During the 5 -week baseline measurements the average heart rate was calculated for each fish with the standard error (SE) both for manual and algorithmic calculated
Table 1 Artificial ECG signal fed at an accurate frequency generated by signal generator to the tag

\begin{tabular}{lll}
\hline Frequency-bpm & $\begin{array}{l}\text { Manual calculation } \\
\text { [bpm] }\end{array}$ & $\begin{array}{l}\text { Algorithmic } \\
\text { calculation } \\
\text { [bpm] }\end{array}$ \\
\hline $0.5 \mathrm{~Hz}-30 \mathrm{bpm}$ & 30 & 29 \\
$1 \mathrm{HZ}-60 \mathrm{bpm}$ & 60 & 60 \\
$2 \mathrm{~Hz}-120 \mathrm{bpm}$ & 120 & 120 \\
$3 \mathrm{~Hz}-180 \mathrm{bpm}$ & 180 & 181 \\
$4 \mathrm{~Hz}-240 \mathrm{bpm}$ & 240 & 240 \\
$5 \mathrm{~Hz}-300 \mathrm{bpm}$ & 300 & 300 \\
\hline
\end{tabular}

Manual calculation from the ECG, recorded with the logger and the Algorithmic calculated values presented in bpm. Sampling frequency of the ECG is $100 \mathrm{~Hz}$

measurements. During the stressor experiment the recovery period was determined when 30 -min average had reached the 5-week baseline measurement average.

\section{Results}

Heart-rate calculations

Results from the artificially generated signal showed strong correlation between manual calculation and the value calculated by the algorithm presented in Table 1 in beats per minute $[\mathrm{bpm}]$.

\section{Quality evaluation}

In both the manually calculated ECG recordings and the algorithmic calculated recordings, recordings with $\mathrm{QI}=3$ were eliminated from the data set. Furthermore, in all but two loggers $\mathrm{QI}=1$ and $\mathrm{QI}=2$ were eliminated, as it was presumed that most of the calculated values receiving those grades were incorrect. Amplitude of the QRS waveform was mostly stable throughout the study in all recordings but the amplitude of the QRS waveform differed between individuals from a maximum of $78 \%$ full scale (FS) to a minimum of $3 \%$ (FS), the average amplitude was $28 \%$ FS and noise level 1\% FS. Low frequency motion artifacts and electromyogram (EMG) artifacts were the main source of noise in the recorded signals. 
Figure 2 shows an example of different ECG recordings and their consequent QI value for one of the data loggers.

It was possible to manually calculate heart rate for 18,490 ECG data traces (97\%). For low-quality recordings, only ECG data traces that had at least two consecutive QRS waveforms of expected frequency content and a similar amplitude were included. Figure 2 has an example of where it is possible to manually calculate heart rate from all four ECG traces although QI is graded from 0 to 3. After QI filtering the calculated data, 92,694 heartrate recordings (81\%) were further analyzed for distribution of heart rate values. Overall distribution of the heart rate as well as QI distribution for the whole data set is presented in Fig. 3. The lowest heart rate recorded was $11 \mathrm{bpm}$ with 38 recordings manually calculated below $20 \mathrm{bpm}(0.2 \%)$ in the whole manual data set. The highest manually calculated heart rate was $75 \mathrm{bpm}$, that logger accounted for the majority of heart-rate measurements above $60 \mathrm{bpm}$. The same device also had the biggest difference between the maximum and minimum heart rate, or $63 \mathrm{bpm}$. The QI distribution was the same for ECG records and all algorithmic calculated records. However, there were also individual differences between the QI ratio of individual fish; $89 \%$ being the highest and $43 \%$ the lowest ratio of $\mathrm{QI}=0$.
The eight fish showed both individual periodical variation as well as individual baseline variation of the heart rate during the 5 -week baseline period at $10.2{ }^{\circ} \mathrm{C}$, with mean heart rate ranging from $29.5 \pm 4$ to $48.1 \pm 3.2 \mathrm{bpm}$. Over the course of the 120 -h period at $7.1{ }^{\circ} \mathrm{C}$ the heart rate was on average $10.7 \mathrm{bpm}$ lower than the 5-week baseline measurements (Table 2). Average heart-rate values correlated well between manual calculated values and values calculated by the on-board algorithm with an average difference of $0.1 \mathrm{bpm}$ at $10.2^{\circ} \mathrm{C}$ and $0.6 \mathrm{bpm}$ difference at $7.1^{\circ} \mathrm{C}$.

\section{Stressors experiment}

During a recovery period of $24 \mathrm{~h}$ after being chased and netted, the fish showed about $20 \%$ increase in heart rate from their individual mean heart rate until reaching baseline value after $6 \mathrm{~h}$ on average. Table 3 shows values for absolute maximum calculated heart rate, the maximum heart rate calculated manually from ECG data during the stressors experiment and an average heart rate over 30 min during the peak of the stressors experiment. The last column presents the recovery period for each fish when baseline value with standard error was reached for a 30-min average. Data logger DST 6 stopped recording just before stressor experiment due to a battery failure.
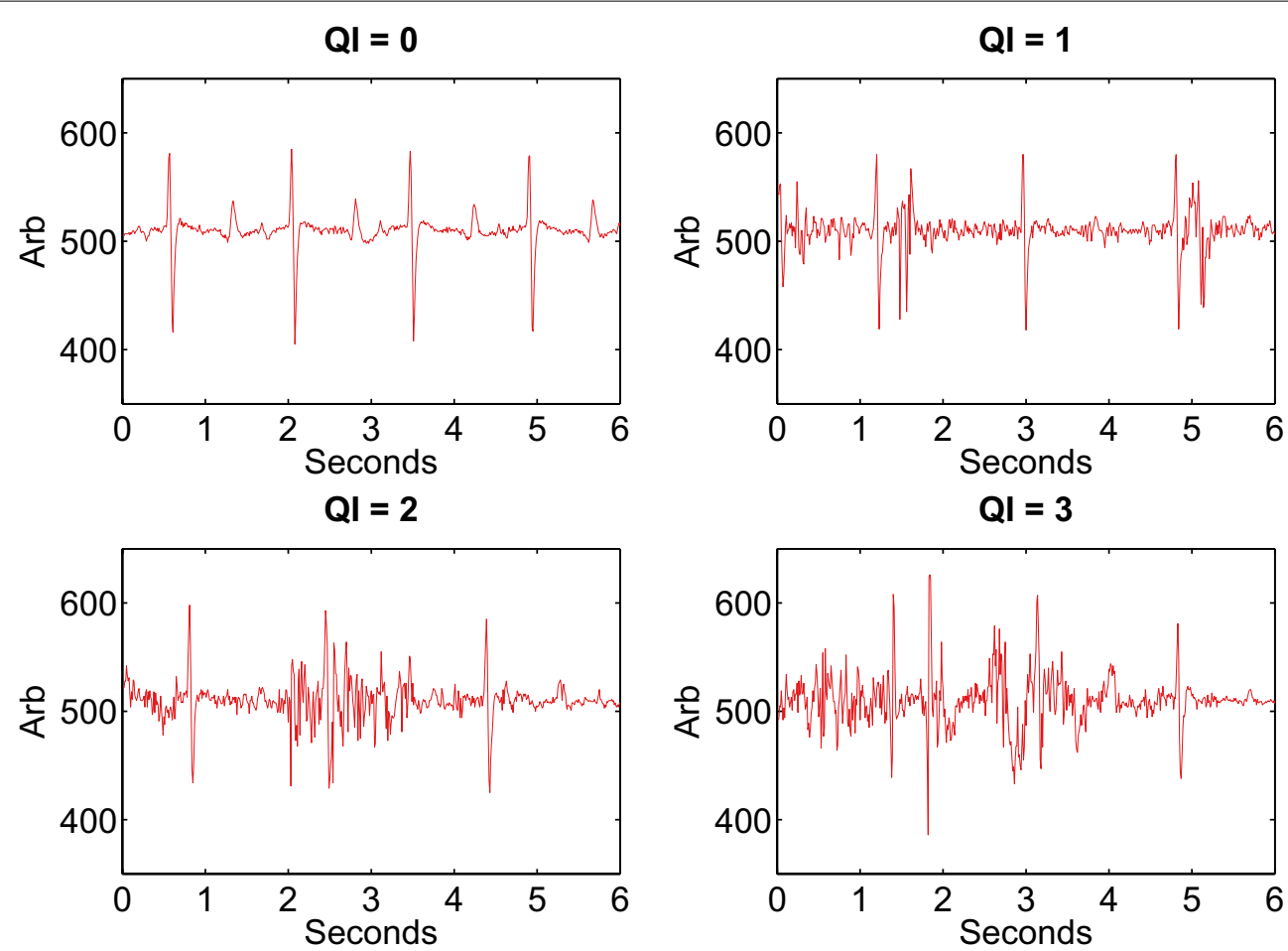

Fig. 2 Examples of ECG data traces with their consequent calculated QI value 

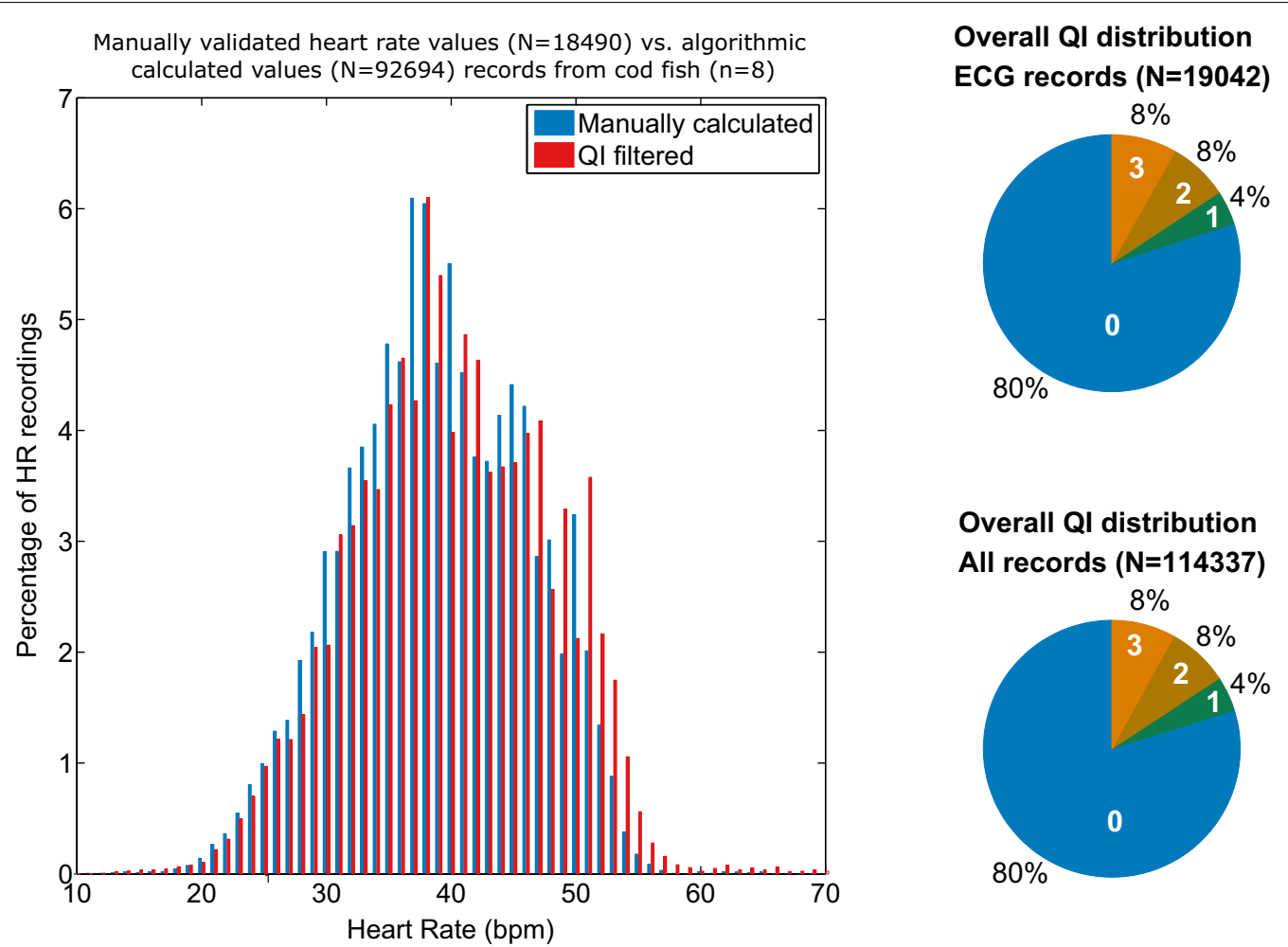

All records $(\mathrm{N}=114337)$

$8 \%$

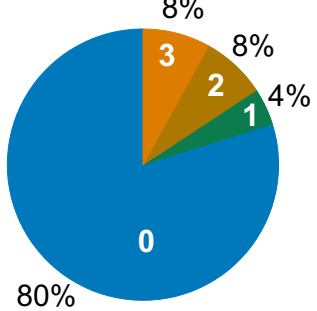

Fig. 3 (left) Percentage of occurring heart rate values, from manually calculated as well as algorithmic calculated values post QI filtering. (right) Distribution of QI for all ECG records (top) and all recorded data (bottom)

Table 2 Average heart rate ( \pm SE) of farmed Atlantic cod for over 5-week baseline period kept at $10.2^{\circ} \mathrm{C}$ and over $120 \mathrm{~h}$ at $7.1^{\circ} \mathrm{C}$

\begin{tabular}{lllllllll}
\hline Logger \# & $\begin{array}{l}\text { Length } \\
{[\mathbf{c m}]}\end{array}$ & Weight $[\mathbf{g}]$ & $\begin{array}{l}\text { Manual } \\
\text { calculation }[\mathrm{BPM}]\end{array}$ & $\begin{array}{l}\text { Algorithm } \\
\text { calculation [BPM] }\end{array}$ & $\begin{array}{l}\text { Temperature } \\
{\left[{ }^{\circ} \mathbf{C}\right]}\end{array}$ & $\begin{array}{l}\text { Manual } \\
\text { calculation [BPM] }\end{array}$ & $\begin{array}{l}\text { Algorithm } \\
\text { calculation [BPM] }\end{array}$ & $\begin{array}{l}\text { Temperature } \\
{\left[{ }^{\circ} \mathbf{C}\right]}\end{array}$ \\
\hline DST 1 & 51 & 1534 & $41.2 \pm 5.3$ & $41.0 \pm 6.4$ & $10.2 \pm 0.1$ & $29.5 \pm 4.1$ & $29.9 \pm 8.2$ & $7.1 \pm 0.1$ \\
DST 2 & 58.5 & 2353 & $36.8 \pm 3.6$ & $36.7 \pm 4.7$ & $10.2 \pm 0.1$ & $28.6 \pm 2.2$ & $28.9 \pm 3.4$ & $7.2 \pm 0.1$ \\
DST 3 & 52 & 1768 & $36.3 \pm 3.72$ & $36.4 \pm 4.7$ & $10.2 \pm 0.1$ & $25.2 \pm 2.7$ & $25.5 \pm 3.9$ & $7.1 \pm 0.1$ \\
DST 4 & 42 & 1203 & $41.8 \pm 3.8$ & $41.3 \pm 3.8$ & $10.2 \pm 0.1$ & $33.1 \pm 3.2$ & $33.8 \pm 4.9$ & $7.1 \pm 0.1$ \\
DST 5 & 45 & 1407 & $48.1 \pm 3.2$ & $48.3 \pm 4.9$ & $10.2 \pm 0.1$ & $37.1 \pm 2.0$ & $37.1 \pm 3.7$ & $7.1 \pm 0.1$ \\
DST 6 & 55 & 2288 & $29.5 \pm 4.0$ & $29.9 \pm 6.3$ & $10.2 \pm 0.1$ & N/A & N/A & N/A \\
DST 7 & 49 & 1762 & $47.2 \pm 4.66$ & $47.2 \pm 5.4$ & $10.2 \pm 0.1$ & $32.0 \pm 2.9$ & $32.0 \pm 3.6$ & $7.1 \pm 0.1$ \\
DST 8 & 54 & 1982 & $39.0 \pm 5.1$ & $39.6 \pm 6.1$ & $10.2 \pm 0.1$ & $30.3 \pm 3.5$ & $32.7 \pm 6.6$ & $7.1 \pm 0.1$ \\
AVERAGE & $50.8 \pm 5$ & $1787 \pm 381$ & $40.0 \pm 4.2$ & $39.9 \pm 5.3$ & $10.2 \pm 0.1$ & $30.8 \pm 2.9$ & $31.4 \pm 4.9$ & $7.1 \pm 0.1$ \\
\hline
\end{tabular}

Figure 4 shows the mean heart rate and temperature for the whole study period; it emphasizes the stressor experiment and shows the influence of temperature on the heart rate.

\section{Discussion}

Measuring temperature, depth and light levels with archival, acoustic and satellite tags has been used extensively in many fish species for more than two decades to monitor the movement and behavior of wild fish [15, 34-36].
The ECG data loggers described in the current study can be implanted in captive as well as wild fish in their natural habitat to provide physiological information that can be of applied interest. In aquaculture Brijs et al. [37, 38] have published work where the loggers have been used to measure stress in rainbow trout during farming practices such as netting and grouping. While Prystay et al. [33] and Wallerius et al. [39] have published work where these heart rate loggers have been used to measure stress due to angling. Presuming that the relationship between 
Table 3 The maximum values from the stressors experiment for each fish, their absolute maximum algorithmic calculated value, maximum manual calculated value, the $30-\mathrm{min}$ average calculated value during peak heart rate and the estimated recovery period

\begin{tabular}{|c|c|c|c|c|c|}
\hline Logger \# & $\begin{array}{l}\text { Baseline value (manual } \\
\text { calculated) [BPM] }\end{array}$ & $\begin{array}{l}\text { Max algorithm heart } \\
\text { rate [BPM] }\end{array}$ & $\begin{array}{l}\text { Max manual heart } \\
\text { rate [BPM] }\end{array}$ & $\begin{array}{l}\text { Average } 30 \text { min max } \\
\text { heart rate }[B P M]\end{array}$ & $\begin{array}{l}\text { Recovery } \\
\text { period [h:min] }\end{array}$ \\
\hline DST 1 & $41.2 \pm 5.3$ & 80 & 55 & 54 & $9 \mathrm{~h}: 45 \mathrm{~min}$ \\
\hline DST 2 & $36.8 \pm 3.6$ & 49 & 56 & 48.6 & 5 h:00 min \\
\hline DST 3 & $36.3 \pm 3.72$ & 61 & 48 & 49.1 & $6 \mathrm{~h}: 20 \mathrm{~min}$ \\
\hline DST 4 & $41.8 \pm 3.8$ & 50 & 53 & 48 & 5 h:20 min \\
\hline DST 5 & $48.1 \pm 3.2$ & 53 & 55 & 52.6 & $6 \mathrm{~h}: 20 \mathrm{~min}$ \\
\hline DST 6 & $29.5 \pm 4.0$ & $\mathrm{~N} / \mathrm{A}$ & $\mathrm{N} / \mathrm{A}$ & $\mathrm{N} / \mathrm{A}$ & $\mathrm{N} / \mathrm{A}$ \\
\hline DST 7 & $47.2 \pm 4.66$ & 56 & 57 & 53 & 3 h:00 min \\
\hline DST 8 & $39.0 \pm 5.1$ & 54 & 52 & 51 & $7 \mathrm{~h}: 40 \mathrm{~min}$ \\
\hline Average & $40.0 \pm 4.2$ & $57.6 \pm 10.7$ & $53.7 \pm 3.0$ & $50.9 \pm 2.4$ & $6 \mathrm{~h}: 12 \mathrm{~min}$ \\
\hline
\end{tabular}

temperature, heart rate and calibrated metabolic rate exist over extended period of time, long-term recordings (e.g., for over a year or more) on wild fish can help establish bioenergy models associated with seasonal variations in feeding, migration and spawning. If the fish gets caught, stress effects of fishing methods can potentially be examined or other human induced stressors such as sound exposure from boats or the use of airguns in offshore seismic exploration [19]. Furthermore such loggers could, for example, be incorporated in future models to investigate response of fish to climate change and to estimate the resilience of fish species to such changes and their acclimation capacity in the wild [2, 40, 41].

When measuring ECG in animals one of the main concerns is how motion artifacts and EMG noise affect the signal recordings. To be able to calculate heart rate from the signal the QRS waveform needs to be easily defined from the noise level of the instrument or other signals categorized as noise in the recording. The sampling frequency used to record the ECG is of essence to be able to filter out unwanted frequencies from the recording. The sampling frequency of $100 \mathrm{~Hz}$ used in this study was sufficient to capture the QRS waveform of Atlantic cod with sufficient resolution to differentiate it from EMG noise due to the low frequency content of the QRS waveform in. Higher sampling frequency will only improve the post processing accuracy of any algorithm.

The duration of each recording at $100 \mathrm{~Hz}$ sampling frequency is $6 \mathrm{~s}$ which sets a limit for lower heart rates. With this sampling frequency the device is unable to record heart rates below $10 \mathrm{bpm}$ and when heart rates fall below $20 \mathrm{bpm}$ there is a possibility that the device is unable to calculate heart rate due to lack of two QRS waveforms. In experiments at lower temperature for Atlantic cod, this sampling frequency becomes a limiting factor to accurately calculate the heart rate unless the recording period can be increased.

This study shows that the average amplitude of the QRS waveform in the recorded ECG signal was around 28\% FS and the lowest amplitude was 3\% FS. However, the noise level is also low, at $1 \% \mathrm{FS}$, which gives a good signal to noise ratio with visible $\mathrm{P}$ and $\mathrm{T}$ wave in most recordings. There are two main ways to increase the amplitude of the QRS waveform apart from surgical placement; that is through amplification, meaning that noise is also amplified, or by placing the electrodes further apart which increases the size and, in most cases, the weight of the instrument. Brijs et al. [37] showed the orientation and distance of the data logger from the heart in rainbow trout during the implantation can have an impact on the amplitude of the signal which would partially explain the variation of the QRS waveform between data loggers in this study.

One-week recovery time from surgery was considered sufficient for the wound to close properly, the logger to stabilize in the tissue and the effect of MS-222 on the behavior and physiology of the fish to be little or nonexistent. However, both the surgical implantation of the data logger, orientation and location, as well as the effect of surgery and anesthesia on the fish should be studied in more detail.

The on-board algorithm was able to correctly calculate up to $81 \%$ of the recorded data with a mean difference of $0.1 \mathrm{bpm}$ and $0.6 \mathrm{bpm}$ depending on the sea temperature which influences the mean heart rate value. This is corroborated when measurements from a precision signal generator are recorded. At $30 \mathrm{bpm}$ the algorithmic calculated value showed $1 \mathrm{bpm}$ difference from manual calculations, but at $60 \mathrm{bpm}$ there was no difference. The algorithmic calculations also showed slightly higher standard deviation compared to the manually calculated 


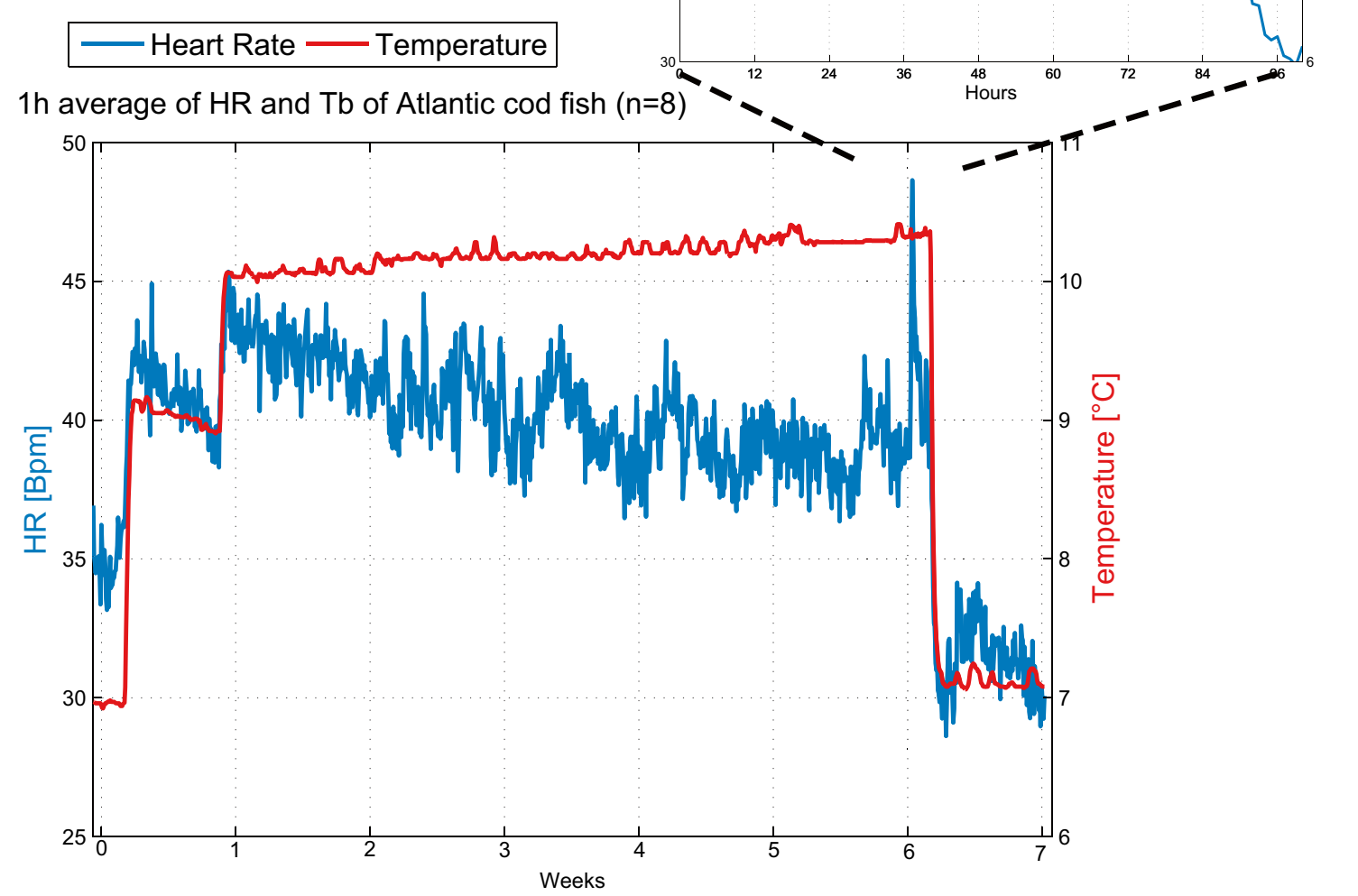

Fig. 4 (bottom) One-hour average heart rate and temperature for all loggers during the whole study period. (top) Magnified $96 \mathrm{~h}$ period where 4-min stress/exercise experiment was conducted

records which is expected based on the larger sample size. Two of the eight loggers had quality index values of 1 and 2 that were not excluded, although noise was present in most of those recording it did not have an impact on the calculated heart rate value, usually covering only a small percentage of the total recording time. However, by manually calculating the QRS interval in the ECG recordings $97 \%$ of the data could be calculated and this indicates that it is possible to improve the on-board algorithm. Brijs et al. [38] compared the heart rate and QI calculations of a milli-HRT data loggers to a reference heart-rate system in rainbow trout (Oncorhynchus mykiss) [ $n=8]$,

1h average of $H R$ and $T b$ of Atlantic cod fish $(n=7)$ during stressors experiment

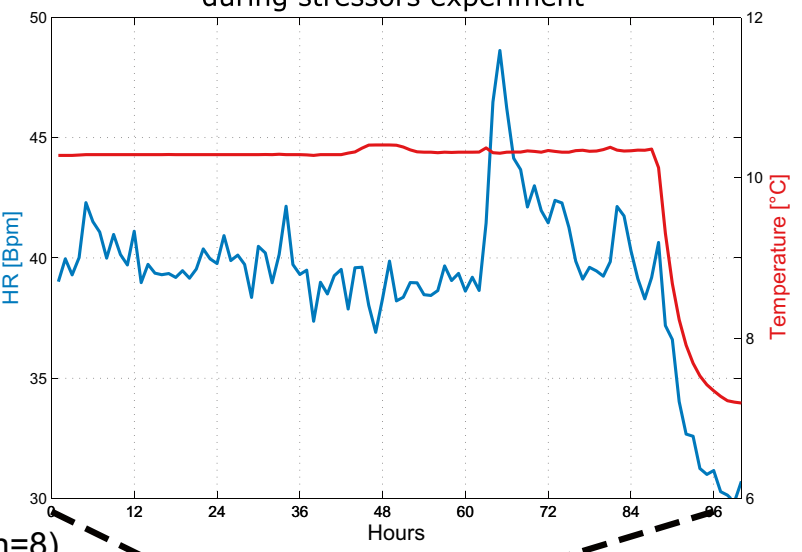


the fish. It is therefore recommended that the sampling interval and sampling frequency of the ECG recordings are increased during studies that include exercise or stress. From the manual recordings of the stressors experiment there was a $34 \%$ increase in heart rate with manual calculations and $44 \%$ increase using the algorithm calculated values. However, the ECG data were recorded every $30 \mathrm{~min}$ and standard heart rate every 5 min which gives a low resolution during an experiment that took only $4 \mathrm{~min}$. Recovery time was $6 \mathrm{~h}$ on average for the fish. Table 3 presented results on absolute maximum and 30-min average maximum heart rate during stressor experiment. The 3-min chase and 1-min air exposure experiment has not been conducted on Atlantic cod while recording heart rate as far as we are aware of. However, Axelson et al. [42] recorded resting and swimming values for Atlantic cod at $10-11{ }^{\circ} \mathrm{C}$. Resting heart rate was $43.2 \pm 1.8 \mathrm{bpm}$ and swimming heart rate was $51.0 \pm 1.7 \mathrm{bpm}$, which is comparable to our results.

During a 5-week baseline period at $10.2^{\circ} \mathrm{C}$ the eight fish showed individual periodical variation where the heart rate would increase for hours up to days in a single fish with no clear external cause. The fish also showed individual baseline variation of the heart rate ranging from $29.5 \pm 4$ to $48.1 \pm 3.2 \mathrm{bpm}$, Davidsen et al. [19] present similar findings when measuring 19 Atlantic cod held in a large sea cage with milli-HRT loggers. This indicates that a sufficient sample size is needed when experimenting with heart rate on Atlantic cod to account for possible intrinsic variation. Finally, when the sea temperature was changed from 10 to $7{ }^{\circ} \mathrm{C}$ in the current study, the mean heart rate decreased from 40 to $30.8 \mathrm{bpm}$. These results are in accordance with other studies on heart rate in Atlantic cod fish [5, 43].

Commercial data loggers that can record ECG in fishes or animals underwater have been large in the past, thus limiting the size of the study animal. The device presented in this study $(11.8 \mathrm{~g})$ also has an even smaller version $(3.3 \mathrm{~g})$ that uses the same algorithm to calculate heart rate and quality index. This smaller device opens up an even larger domain of fishes and aquatic animals to be studied [44]. Transmitting raw ECG data through low-power acoustic transmission or low-power satellite transmission is challenging with currently available commercial technology due to the low data rate versus the high sampling frequency and recording time of an ECG recording. Being able to transmit a heart rate and quality index value from an animal model that has been validated thoroughly in captivity may allow a reduced number of animals to be used for each experiment. That is in accordance to the 3Rs principles; since there are more options to retrieve the data.

\section{Conclusions}

This study presented a validation of an implantable commercial data logging device in Atlantic cod that records ECG and can calculate both heart rate and a novel quality index for the ECG record with an on-board algorithm. In the data presented it was possible to calculate $97 \%$ of the recorded ECG data (19,042 recordings) manually. While using the quality index, $81 \%$ of the total algorithmic calculated values $(114,357)$ were considered correct.

Being able to store only the heart rate and quality index instead of the raw ECG, limits the amount of data that can be processed correctly from each fish. However, it opens possibilities to reduce the size of the recording device to study smaller subjects in the wild as well as transmitting the data through low-power radio frequency, acoustic or satellite transmissions commonly used in fish and wildlife research.

\section{Acknowledgements}

The authors acknowledge Anna Veronika Bjarkadóttir for assistance in writing the manuscript, and the staff at the MFRI Aquaculture Research Station in Grindavik. Also we want to acknowledge the two anonymous reviewers for number of valuable comments on the manuscript.

\section{Authors' contributions}

ÁB designed the study, conducted fieldwork, analyzed data, and drafted the manuscript; TÁ and ÁG conducted fieldwork and contributed substantially in drafting and editing the manuscript; $M O$ conducted fieldwork; AG and AS analyzed data. All authors read and approved the final manuscript.

\section{Funding}

No funding was received.

Availability of data and materials

All data are available at request from authors.

\section{Ethics approval and consent to participate}

This research was conducted with the approval of the Marine and Freshwater Research Institute of Iceland in accordance with a license issued by the Icelandic Food and Veterinary Authority.

\section{Competing interests}

$A ́ B, A G$ and $A S$ are employees of Star-Oddi manufacturer of the logging device. All other authors have no competing interests.

\section{Author details \\ ${ }^{1}$ Star-Oddi Ltd., Garðabær, Iceland. ${ }^{2}$ Marine and Freshwater Research Institute, Grindavik, Iceland. ${ }^{3}$ Marine and Freshwater Research Institute, Reykjavík, Iceland.}

Received: 1 June 2018 Accepted: 4 August 2019

Published online: 12 August 2019

\section{References}

1. Clark TD, Sandblom E, Jutfelt F. Aerobic scope measurements of fishes in an era of climate change: respirometry, relevance and recommendations. J Exp Biol. 2013;216:2771-82. https://doi.org/10.1242/jeb.084251.

2. Sandblom E, Grans A, Axelsson M, Seth $H$. Temperature acclimation rate of aerobic scope and feeding metabolism in fishes: implications in a thermally extreme future. Proc R Soc B Biol Sci. 2014;281:20141490. https ://doi.org/10.1098/rspb.2014.1490.

3. Mendonça PC, Gamperl AK. The effects of acute changes in temperature and oxygen availability on cardiac performance in winter flounder 
(Pseudopleuronectes americanus). Comp Biochem Physiol A Mol Integr Physiol. 2010;155:245-52.

4. Vornanen $\mathrm{M}$. The temperature dependence of electrical excitability in fish hearts. J Exp Biol. 2016;219:1941-52. https://doi.org/10.1242/jeb.128439.

5. Claireaux G, Webber D, Kerr S, Boutilier R. Physiology and behaviour of free-swimming Atlantic cod (Gadus morhua) facing fluctuating temperature conditions. J Exp Biol. 1995;198:49-60.

6. Campbell HA, Taylor EW, Egginton S. The use of power spectral analysis to determine cardiorespiratory control in the short-horned sculpin Myoxocephalus scorpius. J Exp Biol. 2004;207:1969-76. https://doi.org/10.1242/ jeb.00972.

7. Eliason EJ, Clark TD, Hague MJ, Hanson LM, Gallagher ZS, Jeffries KM, et al. Differences in thermal tolerance among sockeye salmon populations. Science. 2011;332:109-12.

8. Farrell AP, Eliason EJ, Sandblom E, Clark TD. Fish cardiorespiratory physiology in an era of climate change. Can J Zool. 2009;87:835-51.

9. Gamperl AK. Integrated responses of the circulatory system: temperature. In: Farell AP, editor. Encyclopedia fish physiology from genome to environment. London: Academic Press; 2011. p. 1197-205.

10. Metcalfe NB, Van Leeuwen TE, Killen SS. Does individual variation in metabolic phenotype predict fish behaviour and performance? J Fish Biol. 2016;88:298-321.

11. Killen SS, Mitchell MD, Rummer JL, Chivers DP, Ferrari MCO, Meekan MG, et al. Aerobic scope predicts dominance during early life in a tropical damselfish. Funct Ecol. 2014;28:1367-76.

12. Thorarensen $\mathrm{H}$, Gallaugher PE, Farrell AP. The limitations of heart rate as a predictor of metabolic rate in fish. J Fish Biol. 1996:49:226-36.

13. Lefrancois C, Claireaux G, Lagardere JP. Heart rate telemetry to study environmental influences on fish metabolic expenditure. Hydrobiologia. 1998;371:215-24

14. Armstrong JD. Relationships between heart rate and metabolic rate of pike: integration of existing data. J Fish Biol. 1998;52:362-8.

15. Cooke SJ, Brownscombe JW, Raby GD, Broell F, Hinch SG, Clark TD, et al. Remote bioenergetics measurements in wild fish: opportunities and challenges. Comp Biochem Physiol Part A Mol Integr Physiol. 2016;202:23-37. https://doi.org/10.1016/j.cbpa.2016.03.022.

16. Pálsson ÓK, Thorsteinsson V. Migration patterns, ambient temperature, and growth of Icelandic cod (Gadus morhua): evidence from storage tag data. Can J Fish Aquat Sci. 2003;60:1409-23. https://doi.org/10.1139/f03-117.

17. Neat FC, Bendall V, Berx B, Wright PJ, Cuaig M, Townhill B, et al. Movement of Atlantic cod around the British Isles: implications for finer scale stock management. J Appl Ecol. 2014:51:1564-74.

18. Sólmundsson J, Jónsdóttir IG, Björnsson B, Ragnarsson SÁ, Tómasson GG, Thorsteinsson V. Home ranges and spatial segregation of cod Gadus morhua spawning components Home ranges and spatial segregation of cod Gadus morhua spawning components. Mar Ecol Prog Ser. 2015:520:217-33.

19. Davidsen JG, Dong H, Linné M, Andersson MH, Piper A, Prystay TS, Hvam EB, Thorstad EB, Whoriskey F, Cooke SJ, Sjursen AD, Rönning L, Netland TC, Hawkins AD. Effects of sound exposure from a seismic airgun on heart rate, acceleration and depth use in free-swimming Atlantic cod and saithe. Conserv Physiol. 2019;7(1):coz020.

20. Priede IG. Heart rate telemetry from fish in the natural environment Comp Biochem Physiol Part A Physiol. 1983;76:515-24.

21. Altimiras J, Larsen E. Non-invasive recording of heart rate and ventilation rate in rainbow trout during rest and swimming. Fish go wireless! J Fish Biol. 2000:57:197-209.

22. Lefrançois C, Claireaux G. Influence of ambient oxygenation and temperature on metabolic scope and scope for heart rate in the common sole Solea solea. Mar Ecol Prog Ser. 2003;259:273-84.

23. Clark TD, Sandblom E, Hinch SG, Patterson DA, Frappell PB, Farrell AP. Simultaneous biologging of heart rate and acceleration, and their relationships with energy expenditure in free-swimming sockeye salmon (Oncorhynchus nerka). J Comp Physiol B Biochem Syst Environ Physiol. 2010;180:673-84.

24. Cook SJ, Bunt CM, Schreer JF, Philipp DP. Attachment, validation and preliminary deployment of ultrasonic heart rate transmitters on largemouth bass, Micropterus salmoides. Aquat Living Resour. 2002;15:155-62.

25. Campbell HA, Bishop CM, Davies DA, Egginton S. Recording long-term heart rate in Paranotothenia angustata using an electronic datalogger. J Fish Biol. 2005:67:1150-6.
26. Claireaux $\mathrm{G}$, Lefrançois $\mathrm{C}$. A method for the external attachment of acoustic tags on roundfish. Hydrobiologia. 1998;371(372):113-6.

27. Anderson WG, Booth R, Beddow TA, McKinley RS, Finstad B, Økland F, Scruton D. Remote monitoring of heart rate as a measure of recovery in angled Atlantic salmon, Salmo salar (L.). Hydrobiologia. 1998;371/372:233-40

28. Clark TD, Ryan T, Ingram BA, Woakes AJ, Butler PJ, Frappell PB. Factorial aerobic scope is independent of temperature and primarily modulated by heart rate in exercising murray cod (Maccullochella peelii peelii). Physiol Biochem Zool Ecol Evol Approach. 2005;78(3):347-55.

29. Woakes AJ, Butler PJ, Bevan RM. Implantable data logging system for heart rate and body temperature: its application to estimation of field metabolic rates in Antarctic predators. Med Biol Eng Comput. 1995:33:145-51.

30. Hellström G, Klaminder J, Jonsson M, Fick J, Brodin T. Upscaling behavioural studies to the field using acoustic telemetry. Aquat Toxicol. 2016;170:384-9.

31. Pan J, Tompkins WJ. A real-time QRS detection algorithm. IEEE Trans Biomed Eng. 1985;BME-32:230-6.

32. Robinson KA, Hinch SG, Gale MK, ClarkTD, Wilson SM, Donaldson MR, et al. Effects of post-capture ventilation assistance and elevated water temperature on sockeye salmon in a simulated capture-and-release experiment. Conserv Physiol. 2013;1:1-10.

33. Prystay TS, Eliason EJ, Lawrence MJ, Dick M, Brownscombe JW, Patterson DA, et al. The influence of water temperature on sockeye salmon heart rate recovery following simulated fisheries interactions. Conserv Physiol. 2017:5:1-12. https://doi.org/10.1093/conphys/cox050/4091321.

34. Brill RW, Block BA, Boggs CH, Bigelow KA, Freund EV, Marcinek DJ. Horizontal movements and depth distribution of large adult yellowfin tuna (Thunnus albacares) near the Hawaiian Islands, recorded using ultrasonic telemetry: implications for the physiological ecology of pelagic fishes. Mar Biol. 1999;133:395-408.

35. Godø OR, Michalsen K. Migratory behaviour of north-east Arctic cod, studied by use of data storage tags. Fish Res. 2000;48:127-40.

36. Block BA, Teo SLH, Walli A, Boustany A, Stokesbury MJW, Farwell CJ, et al. Electronic tagging and population structure of Atlantic bluefin tuna. Nature. 2005;434:1121-7. https://doi.org/10.1038/nature03463.

37. Brijs J, Sandblom E, Axelsson M, Sundell K, Sundh H, Huyben D, Broström R, Kiessling A, Berg C, Gräns A. The final countdown: continuous physiological welfare evaluation of farmed fish during common aquaculture practices before and during harvest. Aquaculture. 2018:495:903-11.

38. Brijs J, Sandblom E, Rosengren M, Sundell K, Berg C, Axelsson M, Gräns A. Prospects and pitfalls of using heart rate bio-loggers to assess the welfare of rainbow trout (Oncorhynchus mykiss) in aquaculture. Aquaculture. 2019;509:188-97.

39. Wallerius ML, Gräns A, Koeck B, Berger D, Sandblom E, Ekström A, Arlinghaus $\mathrm{R}$, Johnsson Jl. Socially induced stress and behavioural inhibition in response to angling exposure in rainbow trout. Fish Manag Ecol. 2019:00:1-10.

40. Portner H-O, Bock C, Knust R, Lannig G, Lucassen M, Mark FC, Sartoris FJ. Cod and climate in a latitudinal cline: physiological analyses of climate effects in marine fishes. Clim Res. 2008;37:253-70.

41. Pörtner HO, Knust R. Climate change affects marine fishes through the oxygen limitation of thermal tolerance. Science. 2007;315:95-7.

42. Axelsson M, Nilsson S. Blood pressure control during exercise in the atlantic cod, Gadus morhua. J Exp Biol. 1996;126:225-36.

43. Gollock MJ, Currie S, Petersen LH, Gamperl AK. Cardiovascular and haematological responses of Atlantic cod (Gadus morhua) to acute temperature increase. J Exp Biol. 2006;209:2961-70. https://doi.org/10.1242/ jeb.02319.

44. McGaw IJ, Steell SC, Van Leeuwen TE, Eliason EJ, Cooke SJ. Application of miniature heart rate data loggers for use in large free-moving decapod crustaceans: method development and validation. Physiol Biochem Zool. 2017:91:731-9. https://doi.org/10.1086/695839.

\section{Publisher's Note}

Springer Nature remains neutral with regard to jurisdictional claims in published maps and institutional affiliations. 